\title{
Rapid Differential Diagnosis between Extrapulmonary Tuberculosis and Focal Complications of Brucellosis Using a Multiplex Real-Time PCR Assay
}

\author{
María Isabel Queipo-Ortuño ${ }^{1,2 *}$, Juan D. Colmenero ${ }^{3}$, Pilar Bermudez ${ }^{4}$, María José Bravo ${ }^{5}$, Pilar Morata ${ }^{1,2}$ \\ 1 Biochemistry and Molecular Biology Department, Faculty of Medicine, University of Malaga, Malaga, Spain, 2 CIBER Fisiopatología Obesidad y Nutrición (CB06/03) \\ Instituto de Salud Carlos III, Madrid, Spain, 3 Infectious Diseases Service, Carlos Haya University Hospital, Malaga, Spain, 4 Microbiology Service, Carlos Haya University \\ Hospital, Malaga, Spain, $\mathbf{5}$ Immunology Service, Carlos Haya University Hospital, Malaga, Spain
}

\begin{abstract}
Background: Arduous to differ clinically, extrapulmonary tuberculosis and focal complications of brucellosis remain important causes of morbidity and mortality in many countries. We developed and applied a multiplex real-time PCR assay (M RT-PCR) for the simultaneous detection of Mycobacterium tuberculosis complex and Brucella spp.

Methodology: Conventional microbiological techniques and M RT-PCR for M. tuberculosis complex and Brucella spp were performed on 45 clinical specimens from patients with focal complications of brucellosis or extrapulmonary tuberculosis and 26 control samples. Fragments of $207 \mathrm{bp}$ and $164 \mathrm{bp}$ from the conserved region of the genes coding for an immunogenic membrane protein of $31 \mathrm{kDa}$ of $B$. abortus (BCSP31) and the intergenic region SenX3-RegX3 were used for the identification of Brucella and M. tuberculosis complex, respectively.

Conclusions: The detection limit of the M RT-PCR was 2 genomes per reaction for both pathogens and the intra- and interassay coefficients of variation were $0.44 \%$ and $0.93 \%$ for Brucella and $0.58 \%$ and $1.12 \%$ for Mycobacterium. M RT-PCR correctly identified 42 of the 45 samples from patients with tuberculosis or brucellosis and was negative in all the controls. Thus, the overall sensitivity, specificity, PPV and NPV values of the M RT PCR assay were $93.3 \%, 100 \%, 100 \%$ and $89.7 \%$, respectively, with an accuracy of $95.8 \%$ (95\% CI, 91.1\%-100\%). Since M RT-PCR is highly reproducible and more rapid and sensitive than conventional microbiological tests, this technique could be a promising and practical approach for the differential diagnosis between extrapulmonary tuberculosis and focal complications of brucellosis.
\end{abstract}

Citation: Queipo-Ortuño MI, Colmenero JD, Bermudez P, Bravo MJ, Morata P (2009) Rapid Differential Diagnosis between Extrapulmonary Tuberculosis and Focal Complications of Brucellosis Using a Multiplex Real-Time PCR Assay. PLoS ONE 4(2): e4526. doi:10.1371/journal.pone.0004526

Editor: Adam J. Ratner, Columbia University, United States of America

Received October 9, 2008; Accepted January 5, 2009; Published February 19, 2009

Copyright: (c) 2009 Queipo-Ortuño et al. This is an open-access article distributed under the terms of the Creative Commons Attribution License, which permits unrestricted use, distribution, and reproduction in any medium, provided the original author and source are credited.

Funding: This work received financial support from the Instituto de Salud Carlos III (ISCIII), F.I.S (grant PI06/0495), and the Consejerí-a de Innovación Ciencia y Empresa (grant CTS-276 and P-08 CTS 3969), both of the Junta de Andalucí-a (Spain). The funders had no role in study design, data collection and analysis, decision to publish, or preparation of the manuscript.

Competing Interests: The authors have declared that no competing interests exist.

*E-mail: iqueipo@uma.es

\section{Introduction}

The global burden of tuberculosis remains enormous and brucellosis continues to be the most common zoonotic infection worldwide, representing a major source of human disease [1-2]. Both tuberculosis and brucellosis are granulomatous diseases with great clinical polymorphism. Extrapulmonary forms account for $10 \%$ to $40 \%$ of all cases of tuberculosis [3-4] and focal complications are present in $20 \%$ to $40 \%$ of brucellosis patients [5-6]. Extrapulmonary tuberculosis and focal forms of brucellosis have been described in almost all organs and systems, with osteoarticular, genitourinary, hepatic or central nervous system involvement being frequent in both diseases [4-5]. Accordingly, in areas of high incidence, a differential diagnosis between both processes is often necessary [7].

Culture remains the gold standard for the diagnosis of tuberculosis and brucellosis. However, as both Brucella spp and Mycobacterium tuberculosis are slowly growing pathogens, cultures are labor intensive, which can at times lead to unacceptable delays in diagnosis. Furthermore, cultures can be very insensitive in some cases of extrapulmonary tuberculosis and focal forms of brucellosis [8-9]. To overcome certain limitations of conventional microbiological techniques, PCR-based assays may be useful for the diagnosis of both tuberculosis and human brucellosis [10-11]. The use of real-time PCR technology reduces the time to identification of bacterial DNA directly from clinical samples. Additionally, considerable time and effort can be saved by simultaneously amplifying multiple sequences in a single reaction. This strategy, named Multiplex PGR, has proven to be very useful in different clinical scenarios [12-13].

The aim of this study was to develop a multiplex real-time PCR (M RT-PCR) assay to simultaneously detect Brucella spp and $M$. tuberculosis complex DNA and analyze its yield in the rapid differential diagnosis between extrapulmonary tuberculosis and certain focal complications of brucellosis. 


\section{Methods}

\section{Bacteria species and strains}

The strains of Brucella used in this study were supplied by the Microbiology Department of the Faculty of Medicine at Valladolid University, except for the vaccine strains B-19 and Rev-1, kindly provided by the Agriculture Department of the Andalusian Regional Government. These strains were cultured on Brucella agar (Difco, USA) and incubated at $37^{\circ} \mathrm{C}$ with $5 \% \mathrm{CO}_{2}$ for $48 \mathrm{~h}$. All non-tuberculous mycobacteria strains except $M$. avium and $M$. celatum were provided by the Colección Española de Cultivos Tipo (CECT) (Valencia, Spain). These strains were grown on Lowenstein-Jensen medium (Biomedics, Spain) at $37^{\circ} \mathrm{C}$ for $2-4$ weeks.

\section{Study population}

Forty-five non-blood clinical specimens from 25 patients with different focal complications of brucellosis and 18 patients with extrapulmonary tuberculosis were studied by M RT-PCR assay. One brucellosis patient who had two different focal complications and another with tuberculous spondylitis and therapeutic failure each provided two different samples.

The samples came from vertebral or other bone tissue (13 patients), lymph nodes (7 patients), tissue or pus from hepatosplenic abscesses (6 patients), cerebrospinal fluid (CSF) (5 patients), synovial fluid (4 patients), urine or kidney tissue (4 patients), pleural fluid (3 patients), pericardial tissue (2 patients) and thyroid tissue (1 patient).

Control samples were obtained from 26 patients with other disorders initially involving a differential diagnosis with extrapulmonary tuberculosis or brucellosis: pyogenic hepatosplenic abscesses (7 patients), septic arthritis (6 patients), pyogenic vertebral osteomyelitis (6 patients), bacterial meningitis (3 patients) and non-tuberculous vertebral osteomyelitis, hepatic Hodgkin lymphoma, kidney abscess and pyogenic pericarditis (1 each).

The diagnosis of brucellosis was established according to one of the following criteria: first, isolation of Brucella spp. from blood or any other body fluid or tissue sample or second, the presence of a compatible clinical picture together with the demonstration of specific antibodies at significant titers or seroconversion. Significant titers were considered to be a standard tube agglutination test (SAT) titer of $\geq 1 / 160$ or an immunocapture agglutination test $\geq 1 / 320$. The diagnosis of tuberculosis was based on isolation of M. tuberculosis or the presence of caseating granulomas, with or without acid-fast bacilli, in a patient with a compatible clinical picture and good therapeutic response to antituberculous treatment.

Ethics Statement. All patients provided written informed consent prior to the collection of biological samples. The utilization of samples for research purposes was approved by the Ethical Committee of Carlos Haya University Hospital, Malaga, Spain.

\section{Microbiological studies}

Two blood cultures were performed for all patients with suspected brucellosis. Blood samples were incubated in a nonradiometric semiautomatic BACTEG 9240 system (Becton Dickinson, Diagnostic Instrument Systems, Sparks, MD), and processed according to usual techniques. All isolates were identified according to normalized protocols [14].

All non-blood samples were stained with Gram, Ziehl-Neelsen and auramine and cultured onto blood and chocolate agar media, MacConkey agar, Brucella agar Lowenstein-Jensen and/or Middlebrook medium (BACTEG MGIT 960, Becton Dickinson, Diagnostic Systems, Spark, MD). SAT was performed as described
[15] and immunocapture-agglutination test (Brucellacapt; Vircell SL, Sante Fé, Granada) was done following the manufacturer's instructions [16].

\section{DNA extraction}

All samples destined for M RT-PCR were maintained at $-20^{\circ} \mathrm{C}$ until processing. The volume varied depending on the type of sample. DNA was extracted using the UltraClean Tissue DNA isolation Kit (Mo Bio Laboratories). Prior to DNA extraction, homogenized samples from the different tissues, CSF, synovial or pleural fluid and purulent sample collections were resuspended in $1 \mathrm{ml}$ of molecular biology water, mixed and centrifuged at $15000 \times \mathrm{g}$ for $5 \mathrm{~min}$. The supernatant was discarded and the pellet was resuspended with the volume of buffer outlined in the manufacturer's instructions. DNA pellets were resuspended in $50 \mu \mathrm{l}$ molecular biology water and stored at $4{ }^{\circ} \mathrm{C}$ until use. Aliquots of $5 \mu \mathrm{l}$ of the suspension (template DNA) were used for PCR analysis. To monitor contamination, negative controls were included during each DNA extraction procedure.

\section{Real-time PCR primers and probes}

For the detection of Brucella spp, a 207 bp fragment from the conserved region of the gene which encodes an immunogenic membrane protein of $31 \mathrm{kDa}$ of $B$. abortus (BCSP31) specific to the Brucella genus and present in all its biovars was amplified using the primers B1 and B2. Primers M1 and M3 amplifying a sequence of $164 \mathrm{bp}$ based on the intergenic region of the genes coding for a mycobacterial two-component system SenX3-RegX3 were used for the identification of $M$. tuberculosis complex. This DNA target sequence is present in all strains of $M$. tuberculosis complex and is absent from all other non-tuberculous mycobacterial strains. The sequences and positions of the amplification primers and the detection probes are shown in Table 1. Fluorescent hybridization probes were designed to anneal within the gene fragment generated by amplification of the corresponding target. The Brucella hybridization probe set (SB1 and SB2) was fluorescein- and LCRed640-labeled and the M. tuberculosis complex hybridization probe set (SM1 and SM3) was fluorescein-and LCRed705-labeled. An extensive search of several databases, including EMBL and GenBank databases, indicated that neither the primers nor the probes shared significant homology with any known nucleotide sequence. All primers and probes were synthesized by Proligo (Sigma Aldrich).

\section{Real-time PCR assay conditions}

Amplification and melt curve analysis were performed using a LightCycler (Roche Diagnostics, Indianapolis, IN). Reactions were carried out in a total volume of $20 \mu \mathrm{l}$. PCR mixes contained primers and probes at final concentrations of $0.6 \mu \mathrm{M}$ and $0.2 \mu \mathrm{M}$, respectively. FastStart DNA Master Hybridization Probes kit (Roche Molecular Biochemicals, Mannheim, Germany) was used; $4 \mu \mathrm{l}$ of the master mixture and $5 \mu \mathrm{l}$ of DNA samples were loaded into glass capillary tubes. After a short centrifugation $(3000 \times \mathrm{g}$ for $10 \mathrm{~s})$ the sealed capillaries were placed into the LightCycler rotor. After an initial polymerase activation and denaturation step at $95^{\circ} \mathrm{C}$ for $10 \mathrm{~min}$, the samples ran 45 amplification cycles, each comprising denaturation $\left(95^{\circ} \mathrm{C}\right.$ for $\left.10 \mathrm{~s}\right)$, annealing $\left(60^{\circ} \mathrm{C}\right.$ for $20 \mathrm{~s})$, and extension $\left(72^{\circ} \mathrm{C}\right.$ for $\left.10 \mathrm{~s}\right)$ in the LightCycler 2.0 , with a temperature transition rate of $20^{\circ} \mathrm{C} / \mathrm{s}$ for all steps. After completion, a melting curve was recorded by heating to $95^{\circ} \mathrm{C}$ for $0 \mathrm{~s}$ at $20^{\circ} \mathrm{C} / \mathrm{s}$, holding at $41^{\circ} \mathrm{C}$ for $20 \mathrm{~s}$ at $20^{\circ} \mathrm{C} / \mathrm{s}$, and then heating slowly at $0.1^{\circ} \mathrm{C} / \mathrm{s}$ until $85^{\circ} \mathrm{C}$. A final cooling step of $40^{\circ} \mathrm{C}$ for $15 \mathrm{~s}$ was added. The peak melting temperature obtained represented the specific amplified product. Each product was 
Table 1. Nucleotide sequences and positions of primers and probes for amplification and detection of Brucella spp. and $M$. tuberculosis complex for M RT-PCR.

\begin{tabular}{llc}
\hline Oligonucleotide & Sequence & Position \\
\hline B1 up & $5^{\prime}$-ggctcggttgccaatatcaat-3' & $788-810$ \\
B2 down & $5^{\prime}$-gtctgcgaccgatttgatgt-3' & $995-977$ \\
SB1 FL probe & $5^{\prime}$-aggcaacgtctgactgcgtaaagcc -FL-3' & $862-838$ \\
SB2 Red probe & $5^{\prime}$-Red 640 -actccagagcgcccgacttgatcg-Phos-3' & $835-812$ \\
M1 up & $5^{\prime}$-cggctaatcacgacggcac -3' & $1114-1132$ \\
M3 down & $5^{\prime}$-ctcttcctctcgttgtgacctgtt-3' & $1277-1254$ \\
SM1 FL probe & $5^{\prime}$-tggctcttccggcgttgatcgag- FL-3' & $1177-1199$ \\
SM3 Red probe & $5^{\prime}$-Red 705-cctatcacgacgacgagcgacccga-Phos-3' & 164 \\
\hline
\end{tabular}

Red 640- LightCycler Red 640, Red 705- LightCycler Red 705, FL-5,6-carboxifluoresceína.

doi:10.1371/journal.pone.0004526.t001

tested using different fluorometer channels. The dye signal generated by the BCSP31 product was measured at $640 \mathrm{~nm}$ and the SenX3-RegX3 intergenic region product signal was measured at $705 \mathrm{~nm}$ following $60^{\circ} \mathrm{C}, 20 \mathrm{~s}$ annealing incubation.

A compensation data file was created using the LightCyclerColor Compensation Set (Roche Diagnostic, Indianapolis, IN). Fluorescence curves were analyzed with the LightCycler software v. 4.0. To minimize experimental variability, we used the automated second derivate maximum estimation method to determine the amplification crossing point (Cp or threshold cycle) that marked the cycle at which fluorescence of the sample became significantly different from the baseline signal.

Positive controls, included in all tests, comprised serial dilutions of B. abortus B-19 and M. tuberculosis DNA. Negative controls were also included and contained all the elements of the reaction mixture except template DNA. To guarantee the reliability of the results, all samples were processed in duplicate. A sample was defined as positive only when the $\mathrm{Cp}$ value was $\leq 36$ cycles in both replicates and the melting temperature peak was consistent with that produced by the corresponding positive controls. The absence of an amplification curve or a $\mathrm{Cp}$ value $\geq 37$ cycles was considered to indicate a negative sample.

Universal precautions and one-way flow of DNA extraction and amplification were used to prevent contamination. To avoid potential observer bias, the status of each patient for Brucella and Mycobacterium infection was unknown during the PCR assay.

\section{Sequencing of M RT-PCR product}

To confirm the identities of the amplified fragments, the M RTPCR products for Brucella spp and M. tuberculosis complex were sequenced. The ABI PRISM Big Dye Terminator Cycle sequencing reaction kit v. 3.0 (Applied Biosystems, Madrid, Spain) was used for the sequencing reactions. Sequence analysis was by capillary electrophoresis in an ABI PRISM, model 3100 automated sequencer (Applied Biosystems).

\section{Statistical Analysis}

Sensitivity, specificity, positive and negative predictive values, accuracy, likelihood ratios (LR) and 95\% confidence intervals (CI) were calculated using the Twobytwo 1.0 analyzer program.

\section{Results}

\section{Analytical sensitivity}

The M RT-PCR analytical sensitivity was initially determined by amplifying ten-fold serial dilutions of DNA from B. abortus B-19 and $M$. caprae. The detection limit was $2 \times 10^{0}$ genomes per reaction for both pathogens. The assays showed a linear quantitative range over five orders of magnitude from $2 \times 10^{5}$ down to $2 \times 10^{0}$ genomes per reaction, with linear regression equations of $\mathrm{Cp}=-3.37 \mathrm{log}$ (genome number.) +36.92 and $\mathrm{Cp}=-3.32 \log$ (genome number.) +36.89 , correlation coefficients $\left(\mathrm{R}^{2}\right)$ values of 0.99 and a PCR efficiencies (E) of 2.0 for Brucella and Mycobacterium respectively.

\section{Reproducibility}

Intra-assay variability was determined by amplifying, in quadruplicate, dilutions of DNA from $B$. abortus B-19 and $M$. caprae, equivalent to $2 \times 10^{4}$ to $2 \times 10^{0}$ copies per reaction. Threshold cycle values (Cp) obtained for the same dilutions on five different days were used to determine the inter-assay variability. The mean coefficients of variation $(\mathrm{CV})$ for intra-assay repetitions were $0.44 \%$ for Brucella and $0.58 \%$ for $M$. tuberculosis complex, with $\mathrm{CV}$ values of $0.32 \%, 0.74 \%, 0.35 \%, 0.35 \%$ and $0.35 \%, 0.63 \%, 0.65 \%, 0.69 \%$ for the samples with $2 \times 10^{4}, 2 \times 10^{3}$, $2 \times 10^{1}, 2 \times 10^{0}$ copies per reaction of Brucella and Mycobacterium, respectively. The mean inter-assay $\mathrm{CVs}$ for the whole group of samples were $0.93 \%$ for Brucella and $1.12 \%$ for Mycobacterium with CV values of $0.73 \%, 0.80 \% 0.66 \%, 1.14 \%$ and $1.09 \%, 0.91 \%$, $1.21 \%, 1.29 \%$ for the samples with $2 \times 10^{4}, 2 \times 10^{3}, 2 \times 10^{1}, 2 \times 10^{0}$ copies per reaction of Brucella and Mycobacterium, respectively.

\section{Specificity}

To confirm the specificity, we tested different strains of Brucella, M. tuberculosis complex and non-tuberculous Mycobacteria (Table 2). Only amplified fragments from M. tuberculosis complex were detected at a wavelength of $705 \mathrm{~nm}$, indicating the fluorogenic probes were specific for $M$. tuberculosis complex and did not cross-react with Brucella spp or other non-tuberculous Mycobacteria strains. Fluorescent signals at $640 \mathrm{~nm}$ were obtained with all strains of Brucella spp assayed but not with any Mycobacterium strain (Figure 1). The M RT-PCR assay was therefore $100 \%$ specific.

\section{Clinical sensitivity and specificity}

Of the 25 brucellosis patients, diagnosis was established by isolating the pathogen in blood cultures or in cultures of other samples in 17 cases (68\%). For the remaining 8 patients $(32 \%)$, the diagnosis was made by clinical-serological means. All the strains isolated were identified as B. melitensis. Brucella was isolated in nonblood samples in seven patients $(26.9 \%$ ) (two with vertebral 
Table 2. Multiplex PCR results with DNA from different Brucella and Mycobacterium strains.

\begin{tabular}{|c|c|c|c|c|c|}
\hline Species & Biovar & Strain & Origin & M tuberculosis complex & Brucella \\
\hline Brucella melitensis & 1 & $16 M$ & FMV & - & + \\
\hline Brucella melitensis & 1 & $\operatorname{Rev} 1$ & CAJA & - & + \\
\hline Brucella melitensis & 2 & $63 / 9$ & FMV & - & + \\
\hline Brucella melitensis & 3 & Ether & FMV & - & + \\
\hline Brucella melitensis & 2 & (clinical strain) & FMV & - & + \\
\hline Brucella melitensis & 3 & (clinical strain) & FMV & - & + \\
\hline Brucella abortus & 1 & (clinical strain) & FMV & - & + \\
\hline Brucella abortus & 1 & B19 & CAJA & - & + \\
\hline Brucella abortus & 2 & $86 / 8 / 59$ & FMV & - & + \\
\hline Brucella abortus & 3 & Tulya & FMV & - & + \\
\hline Brucella abortus & 4 & 292 & FMV & - & + \\
\hline Brucella abortus & 5 & B3196 & FMV & - & + \\
\hline Brucella abortus & 6 & 870 & FMV & - & + \\
\hline Brucella abortus & 7 & $63 / 75$ & FMV & - & + \\
\hline Brucella abortus & 9 & $\mathrm{C} / 68$ & FMV & - & + \\
\hline Brucella suis & 1 & 10036 & FMV & - & + \\
\hline Brucella suis & 2 & 10510 & FMV & - & + \\
\hline Brucella suis & 3 & 10511 & FMV & - & + \\
\hline Brucella suis & 4 & 40 & FMV & - & + \\
\hline Brucella suis & 5 & 10980 & FMV & - & + \\
\hline Brucella neotomae & & 10084 & FMV & - & + \\
\hline Brucella ovis & & Reo198 & FMV & - & + \\
\hline Brucella canis & & 10854 & FMV & - & + \\
\hline Mycobacterium tuberculosis & & 1100 & $\mathrm{HCH}$ & + & - \\
\hline Mycobacterium caprae & & 1040 & $\mathrm{HCH}$ & + & - \\
\hline Mycobacterium africanum & & 1031 & $\mathrm{HCH}$ & + & - \\
\hline Mycobacterium bovis & & 530 & $\mathrm{HCH}$ & + & - \\
\hline Mycobacterium avium & & 1062 & ATCC & - & - \\
\hline Mycobacterium xenopi & & 1071 & $\mathrm{HCH}$ & - & - \\
\hline Mycobacterium kansasii & & 1085 & $\mathrm{HCH}$ & - & - \\
\hline Mycobacterium chelonae & & 1052 & $\mathrm{HCH}$ & - & - \\
\hline Mycobacterium gordonae & & 953 & $\mathrm{HCH}$ & - & - \\
\hline Mycobacterium fortuitum & & 944 & $\mathrm{HCH}$ & - & - \\
\hline Mycobacterium scrofulaceum & & 702 & $\mathrm{HCH}$ & - & - \\
\hline Mycobacterium szulgai & & CC $1 / 07$ & $\mathrm{HCH}$ & - & - \\
\hline Mycobacterium marinum & & 7091 & CECT & - & - \\
\hline Mycobacterium celatum & & 342 & ATCC & - & - \\
\hline Mycobacterium intracellulare & & CC $2 / 04$ & $\mathrm{HCH}$ & - & - \\
\hline Mycobacterium simiae & & 946 & $\mathrm{HCH}$ & - & - \\
\hline Mycobacterium smegmatis & & 3017 & CECT & - & - \\
\hline Mycobacterium flavencens & & 3027 & CECT & - & - \\
\hline Mycobacterium Phlei & & & CECT & - & - \\
\hline
\end{tabular}

FMV, Facultad de Medicina Valladolid, Valladolid, Spain; CAJA, Consejeria de Agricultura, Junta de Andalucia, Seville, Spain; CECT, Colección Española de Cultivos Tipo, Valencia, Spain; HCH, Hospital Carlos Haya, Málaga, Spain. ATCC, American Type Culture Collection.

doi:10.1371/journal.pone.0004526.t002

osteomyelitis and one each with meningitis, pleural empyema, liver abscess, knee arthritis and thyroid abscess). M RT-PCR identified Brucella DNA in $25(96.1 \%)$ of the 26 samples. The patient with a false-negative M RT-PCR experienced a relapse of knee arthritis and from whom $B$. melitensis was isolated in synovial fluid.
Of the 19 samples obtained from patients with tuberculosis, AFB smears were positive in $9(52.9 \%)$ of the 17 cases in which the test was carried out, culture was positive in $14(73.7 \%)$ cases and M RTPCR assay was positive in $17(89.5 \%)$ cases. The two negative M RT-PGR results corresponded to one patient with tuberculous 


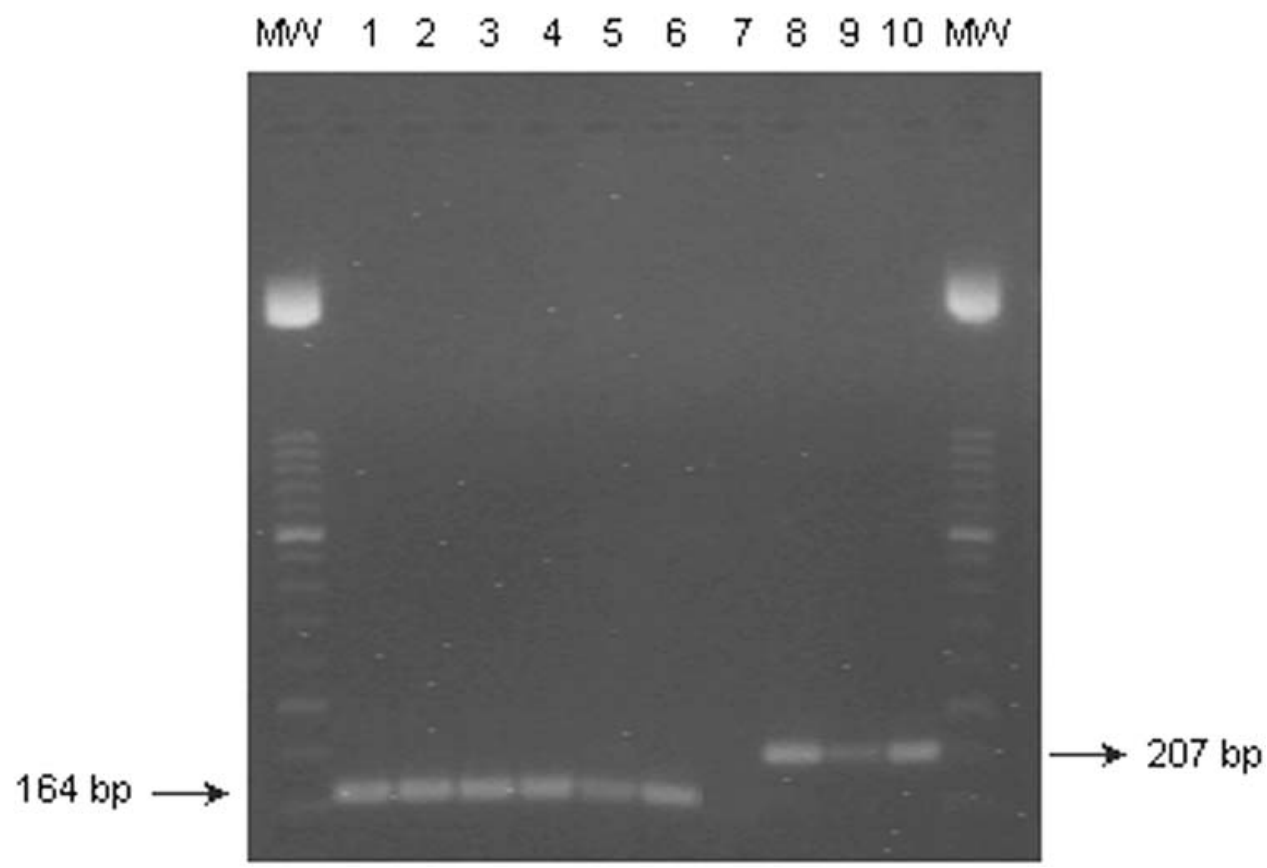

Figure 1. Agarose gel electrophoresis and ethidium bromide staining. Lanes: MW, molecular size DNA ladder XIII; 1, positive control (M. caprae); 2 to 3, DNA from two strains of $M$. tuberculosis complex (M. tuberculosis and $M$. africanum); 4 to 6 , samples of pleural fluid, psoas abscess and urine, respectively, from three patients with tuberculosis; 7, no ADN added; 8 positive control (B. Melitensis Rev-1); 9 to 10, DNA from hepatic abscess and kidney tissue, respectively, from two patients with brucellosis. doi:10.1371/journal.pone.0004526.g001

vertebral osteomyelitis with a negative culture and another with ankle arthritis from which $M$. tuberculosis was isolated in culture.

M RT-PCR was negative in all the controls, including one with HIV and vertebral osteomyelitis due to $M$. xenopi.

Considering the patients with tuberculosis and brucellosis together, the sensitivity, specificity, PPV and NPV values of our M RT PCR assay were 93.3\%, 100\%, 100\% and $89.7 \%$, respectively, with an accuracy of 95.8\% (95\% CI, 91.1\%-100\%) and a negative LR of 0.07 (95\% CI, 0.02-0.2) (Table 3).

The mean Cp was 29.3 \pm 4.6 cycles in the patients with Brucella and $30.5 \pm 5.5$ cycles for those with tuberculosis. In both cases melting temperature analysis confirmed the nature of the amplified product (Figure 2).
The M RT-PCR results were similar when an identical panel of samples was assayed in a double-tube format (Figure 3).

\section{Discussion}

Traditional laboratory techniques for the diagnosis of tuberculosis and brucellosis are far from being sensitive and specific. In the case of tuberculosis, direct microscopy lacks sensitivity and serological diagnosis of brucellosis lacks adequate specificity. Moreover, in both cases, cultures are time consuming and require direct sample handling, representing a risk of infection for laboratory personnel.

Table 3. Diagnostic yield of Multiplex real-Time PCR in clinical specimens from patients with extrapulmonary tuberculosis and focal complications of brucellosis.

\begin{tabular}{|c|c|c|c|}
\hline & All samples & Samples from patients with focal Brucellosis & Samples from patients with extrapulmonary TBC \\
\hline & $\mathbf{N}=45$ & $\mathbf{N}=\mathbf{2 6}$ & $\mathbf{N}=19$ \\
\hline \multicolumn{4}{|l|}{$\%,(95 \% \mathrm{CI})$} \\
\hline Sensitivity & $93.3,(86-100)$ & $96.2,(88.8-100)$ & $89.5,(75.7-100)$ \\
\hline Specificity & 100 & 100 & 100 \\
\hline PPV & 100 & 100 & 100 \\
\hline NPV & 89.7, (78.6-100) & $97.8,(93.6-100)$ & $96.3,(91.3-100)$ \\
\hline Accuracy & $95.8,(91.1-100)$ & 98.6, $(95.9-100)$ & $97.2,(93.3-100)$ \\
\hline Positive LR & $N D^{\mathbf{a}}$ & $N D^{\mathbf{a}}$ & $N D^{\mathbf{a}}$ \\
\hline Negative LR & $0.07,0.02-0.20$ & $0.04,0.01-0.26$ & $0.11,0.03-0.39$ \\
\hline
\end{tabular}

$P P V=$ positive predictive value; NPV = negative predictive value; Positive $L R=$ positive likelihood ratio, Negative $L R=$ negative likelihood ratio. a not done for mathematical reasons (division by zero).

doi:10.1371/journal.pone.0004526.t003 


\section{Amplification Curves}

A

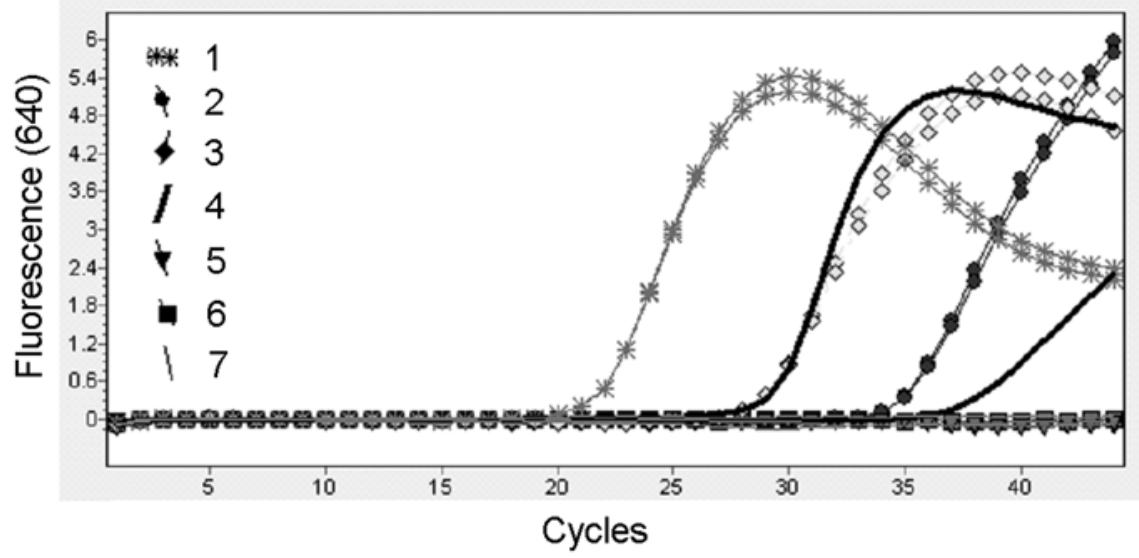

B

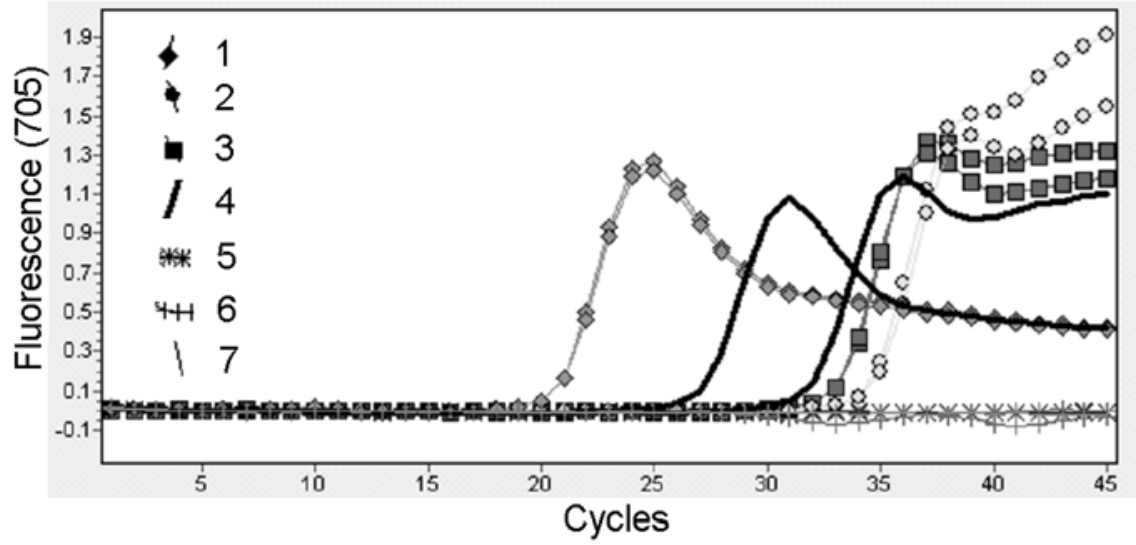

Melting Peaks
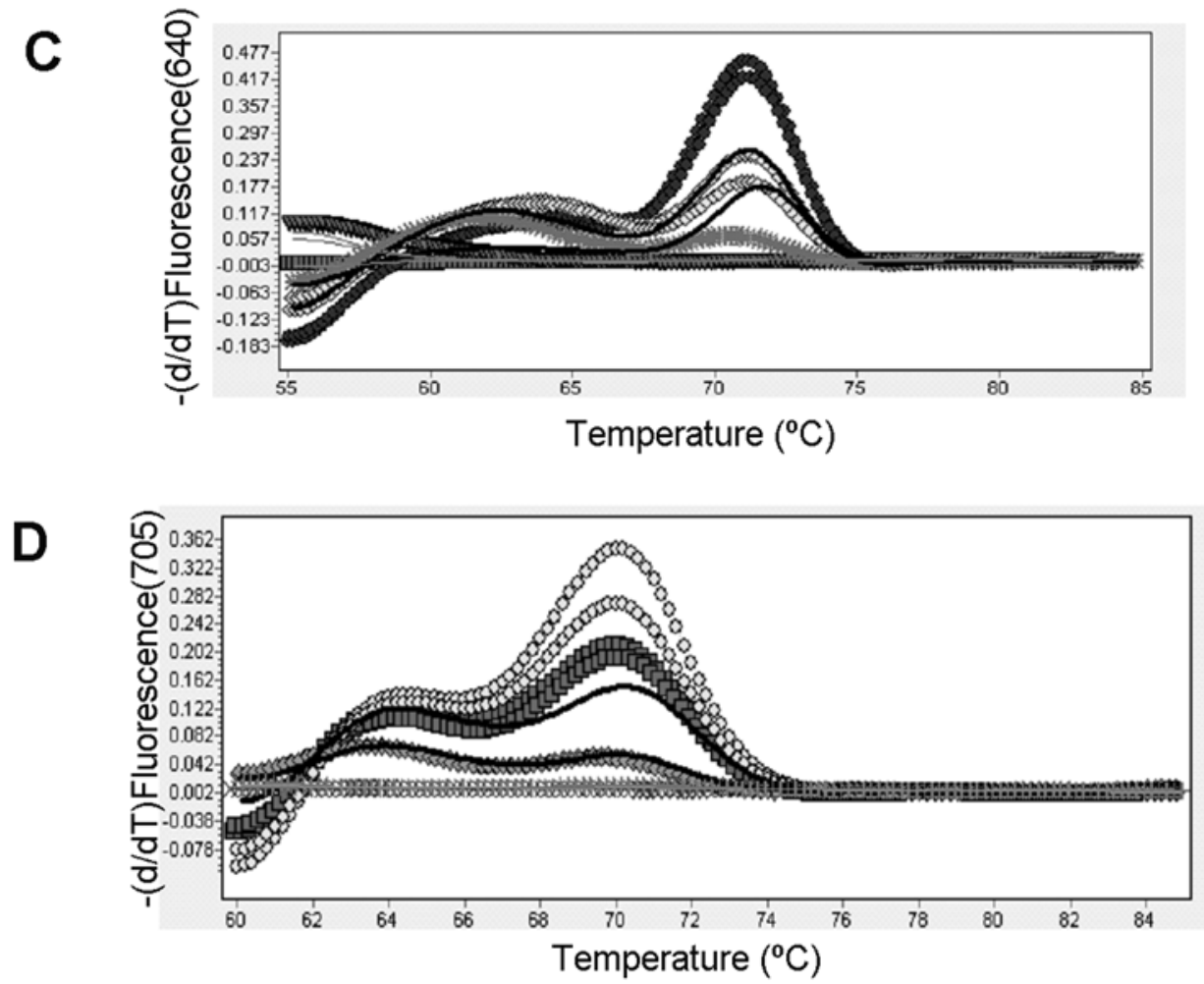
Figure 2. Evaluation of the M RT-PCR assay with clinical samples. A representative set of clinical samples was simultaneously tested for the BCSP31 gene for Brucella spp (A) and the intergenic region SenX3-RegX3 for M. tuberculosis complex (B). Panel (A) Samples 1,2 and 3 were pleural fluid, hepatic abscess and urine, respectively, corresponding to brucellosis patients; sample 7 was CSF, from a patient with S. pneumoniae meningitis; and samples 4 and 5, positive controls for Brucella and $M$ tuberculosis complex, respectively. Sample 6, negative control. Panel (B). Samples 1, 2 and 3 were lymph node, pericardial tissue and psoas abscess, respectively, corresponding to tuberculosis patients; sample 7 was of vertebral tissue, from a patient with S. agalatiae pyogenic vertebral osteomyelitis; and samples 4 and 5, positive controls for M. tuberculosis complex and Brucella, respectively. Sample 6, negative control. Panels (C) and (D). Melting curves of the amplified fragments generated by M RT-PCR. Specific signals for brucellosis patients and positive controls had melting temperatures of $71.51 \pm 0.18^{\circ} \mathrm{C}$ and $71.12 \pm 0.13^{\circ} \mathrm{C}$ for tuberculosis patients and positive controls.

doi:10.1371/journal.pone.0004526.g002

PCR has revolutionized the field of infectious disease diagnosis. Molecular techniques have proven more sensitive than conventional methods in both tuberculosis and human brucellosis [1011,17-20]. Real-time PCR technology has provided an opportunity to develop an assay that meets the requirements for rapid diagnosis, thus increasing the interest of clinical laboratories in molecular diagnosis [21].

Multiplex polymerase chain reaction is a variant of PCR in which two or more target sequences can be simultaneously amplified. Multiplex PGR has the potential to produce considerable savings in time and effort in the laboratory. This method has been successfully applied in many areas of DNA testing, including the field of infectious diseases [22]. From a clinical and microbiological point of view, multiplex PCR would be specially useful in those scenarios in which several agents cause similar clinical syndromes.

Numerous PCR assays employing a number of different $M$. tuberculosis and Brucella spp targets have recently been described [23-24]. For the detection of Brucella, we chose a conserved region of the gene encoding for BCSP31, the target with the most clinical experience [11,25-26]. For tuberculosis, we opted for specificity. The IS6110 multicopy insertion element, the most widely used target sequence of the $M$. tuberculosis genome, does not allow specific identification of $M$. tuberculosis [27]. Moreover, $M$. tuberculosis strains lacking the IS 6110 element have been described [28]. Accordingly, we selected a sequence of the SenX3-RegX3 intergenic region (IR) which contains mycobacterial interspersed repetitive units (MIRUs), described only for mycobacterial species belonging to the M. tuberculosis complex [29-30].

Our results demonstrate the specificity of M RT-PCR. All the strains of Brucella spp and M. tuberculosis complex showed clear DNA amplification, confirmed by melting curve analysis and sequencing the amplified products, which perfectly matched the $207 \mathrm{bp}$ and 164 bp fragments corresponding to B. abortus and the SenX3-RegX3 intergenic region of $M$. tuberculosis complex. No cross-reaction occurred with any of the strains of the wide panel of non-tuberculous micobacteria tested. These results agree with those of Broccolo et al [29] and appear to confirm that the amplification of a DNA fragment belonging to the SenX3-RegX3 IR is very specific and allows for a more precise identification of the $M$. tuberculosis complex species.

Under the conditions used, the precision of our M RT-PCR can be considered very high, as the intra-assay variation was lower than $1 \%$ and the inter-assay variation around $2 \%$. Bearing in mind that the inoculum found in clinical samples from patients with extrapulmonary tuberculosis or focal complications of brucellosis could be very small, the detection capacity of any multiplex PCR assay used in these diagnoses needs to be very high. The analytical sensitivity of our M RT-PCR, 2 genome equivalents, can also be considered very good, as it is similar or higher than that of conventional PCR procedures previously used for the diagnosis of tuberculosis or brucellosis. Such small amounts of DNA can be expected in any clinical sample from a patient with active extrapulmonary tuberculosis or focal brucellosis.

Numerous studies have assessed the yield of PCR techniques for the diagnosis of extrapulmonary tuberculosis [10,18-20] and a few others for focal complications of brucellosis $[11,17]$. Nevertheless, this is the first study designed to verify the usefulness of multiplex technology applied to the rapid differential diagnosis between extrapulmonary tuberculosis and focal complications of brucellosis. Overall, the sensitivity and specificity of our M RT-PCR were very high, correctly identifying $93.3 \%$ of the patients with tuberculosis or brucellosis, and showing negative in all the controls. Individually, the sensitivity in the diagnosis of patients with focal complications of brucellosis was $96.2 \%$, similar to that reported for an in-house PCR assay [11] and far better than culture, for which positivity was again shown to be below $50 \%$. The sensitivity in clinical specimens of extrapulmonary tuberculosis was slightly lower, $89.5 \%$. Even so, this was still higher than most studies, which have used different targets and different amplification strategies and reported sensitivity values of the various PCR techniques from $53.8 \%$ to $85 \%$ [10,18-20].

Apart from its high sensitivity, M RT-PCR provides the results in just four hours, far less than that required for isolation of Brucella and $M$. tuberculosis. The mean time for isolation and identification of Brucella in a non-blood sample was 5.8 \pm 2.6 days and for $M$. tuberculosis it was $21.5 \pm 6.8$ and $9.5 \pm 4.4$ days, depending on whether solid or liquid media were used, respectively. Even assuming that culture is the gold standard for diagnosis of tuberculosis and that it is the only method enabling a study of strain sensitivity to treatment, this drastic reduction in diagnostic delay has important prognostic implications in severe cases, such as meningitis or vertebral osteomyelitis.

Finally, like other molecular techniques, M RT-PGR is very versatile, as samples can be stored at $-20^{\circ} \mathrm{C}$ until processing and it almost completely obviates the need for direct handling of the pathogens, thus drastically reducing the risk of infection of laboratory personnel.

One limitation of this study is the reduced sample size and the diversity of the samples used. Caution should therefore be exercised with definitive interpretation of the results. Nevertheless, this is a frequent problem with diseases with a relatively low incidence and whose form of presentation is very heterogeneous.

In conclusion, under the conditions used here, M RT-PCR seems to be sensitive and specific, which, coupled with its speed and versatility, make this technique a very useful tool for the differential diagnosis between extrapulmonary tuberculosis and certain focal complications of brucellosis.

\section{Acknowledgments}

We thank Ian Johnstone for his help with the English language version of the text.

\section{Author Contributions}

Conceived and designed the experiments: MIMQO JDC PPB MJB PM. Performed the experiments: MIMQO JDC PPB MJB PM. Analyzed the data: MIMQO JDC PPB MJB PM. Contributed reagents/materials/ analysis tools: MIMQO JDG PPB MJB PM. Wrote the paper: MIMQO JDC PPB MJB PM. 
Amplification Curves

A

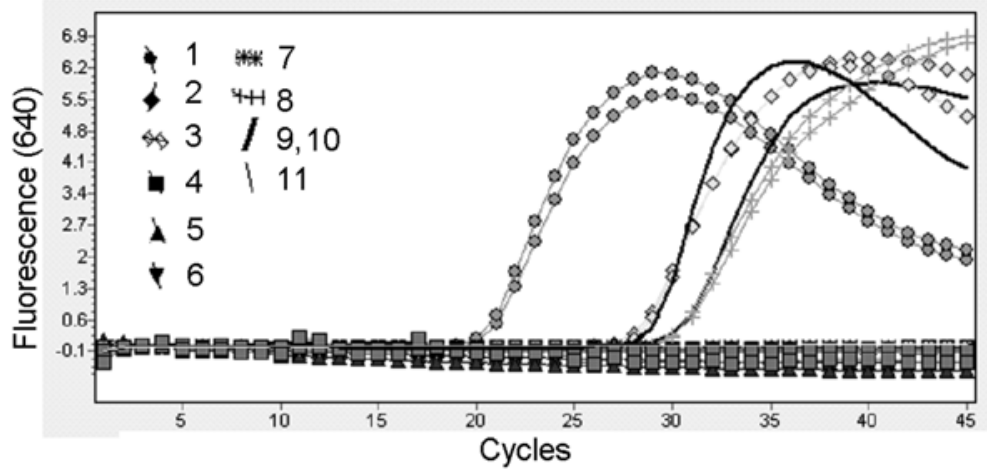

B

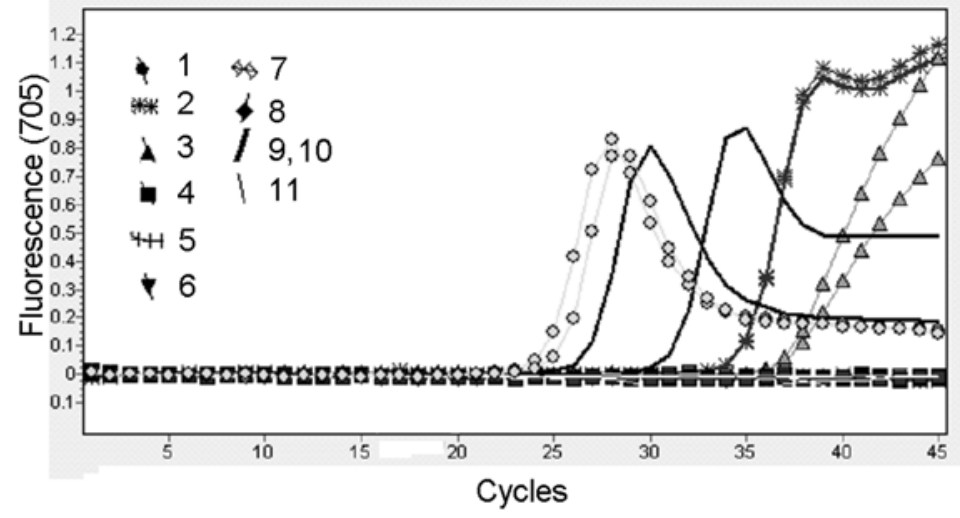

Melting Peaks

C

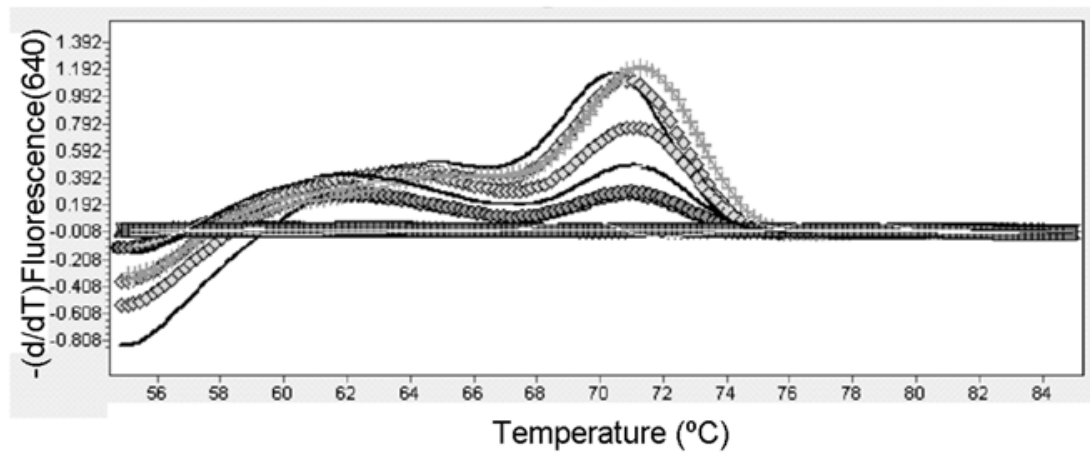

D

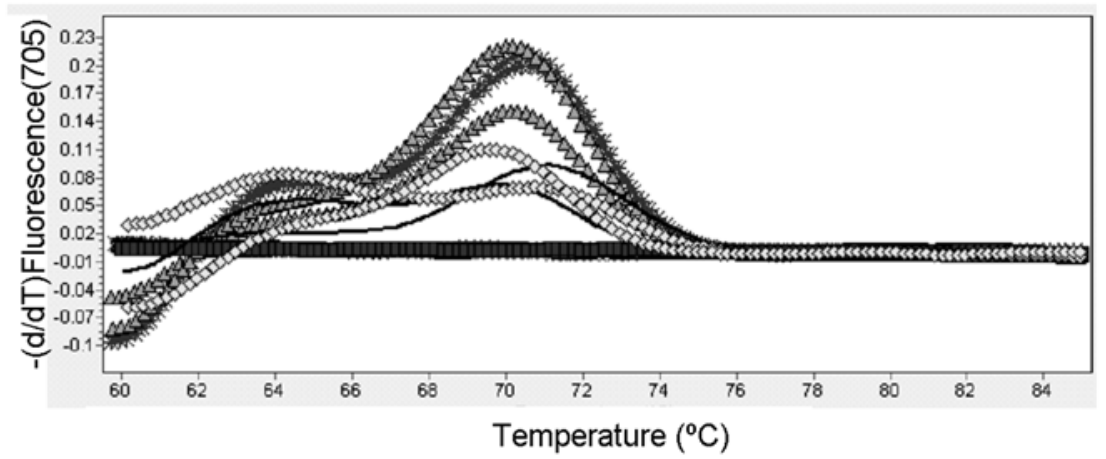


Figure 3. Double-tube format RT-PCR assay with identical clinical samples to those described in Figure 2. All reactions were optimized to obtain the best amplification kinetics under the same cycling conditions and reaction mixture compositions, as described in the Methods section. Panel (A) Clinical samples tested for the BCSP31 gene for Brucella spp. Samples 1, 2 and 3 were pleural fluid, hepatic abscess and urine, respectively, corresponding to brucellosis patients. Sample 4 was CSF, from a patient with S. pneumoniae meningitis; and samples 5, 6 and 7 were lymph node, pericardial tissue and psoas abscess, respectively, corresponding to tuberculosis patients, and sample 8 was of vertebral tissue from a patient with $S$. agalatiae pyogenic vertebral osteomyelitis. Samples 9 and 10, positive controls for Brucella. Sample 11, negative control. Panel (B). Clinical samples assayed for the intergenic region SenX3-RegX3 for M. tuberculosis complex, Samples 1 to 8 were identical to those described in panel A. Samples 9 and 10, positive controls for $M$. tuberculosis complex. Sample 11, negative control. Panels (C) and (D). Melting curves of the amplified fragments generated by RT-PCR in double-tube format.

doi:10.1371/journal.pone.0004526.g003

\section{References}

1. Day C (2006) Global epidemiology of tuberculosis. Lancet 367: 938-940.

2. Corbel MJ (1997) Brucellosis an overview. Emerg Infect Dis 3: 213-221.

3. Dolberg OT, Schlaeffer F, Greene VW, Alkan ML (1991) Extrapulmonary tuberculosis in an immigrant society: clinical and demographic aspects of 92 cases. Rev Infect Dis 13: 177-179.

4. Denis-Delpierre N, Merrien D, Billaud E, Besnier JM, Duhamel E, et al. (1998) Extrapulmonary tuberculosis in the central western region. Retrospective study of 217 cases (Gerico 1991-1993). Presse Med 27: 341-346.

5. Colmenero JD, Reguera JM, Martos F, Sánchez-De-Mora D, Delgado M, et al. (1996) Complications associated with Brucella melitensis infection: a study of 530 cases. Medicine 75: 195-211.

6. Pappas G, Akritidis N, Bosilkovski M, Tsianos E (2005) Brucellosis. N EnglJ Med 352: $2325-2336$

7. Franco MP, Mulde M, Robert H, Gilman HR, Smits HL (2007) Human brucellosis. Lancet Infect Dis 7: 775-786.

8. McLean DR, Russell N, Khan Y (1992) Neurobrucellosis. Clinical and therapeutic features. Clin Infect Dis 15: 582-590.

9. Colmenero JD, Jiménez-Mejías ME, Reguera JM, Palomino-Nicás J, RuizMesa JD, et al. (2004) Tuberculous vertebral osteomyelitis in the new millennium: still a diagnostic and therapeutic challenge. Eur J Clin Microbiol Infect Dis 23: 477-483.

10. Hofman V, Selva E, Landraud L, Sicard D, Vénissac N, et al. (2003) Value of PCR amplification from formalin-fixed paraffin-embedded tissues in the diagnosis of Mycobacterium tuberculosis infection. Ann Pathol 23: 206-215.

11. Morata P, Queipo-Ortuño MI, Reguera JM, Miralles F, Lopez-Gonzalez JJ, et al. (2001) Diagnostic Yield of a PCR-assay in Focal Complications of Brucellosis. J Clin Microbiol 39: 3743-3746.

12. Strålin K, Törnqvist E, Kaltoft MS, Olcén P, Holmberg H (2006) Etiologic diagnosis of adult bacterial pneumonia by culture and PCR applied to respiratory tract samples. J Clin Microbiol 44: 643-645.

13. Markoulatos P, Georgopoulou A, Kotsovassilis C, Karabogia-Karaphillides P, Spyrou N (2000) Detection and typing of HSV-1, HSV-2, and VZV by a multiplex polymerase chain reaction. J Clin Lab Anal 14: 214-219.

14. Moyer N, Holcomb PLA (1995) Brucella. In: Murray PR, Baron EJ, Pfaller MA, Tanover FC, Yolken RH, eds. Manual of clinical microbiology. 6th ed. Washington, DC: American Society for Microbiology. pp 382-386.

15. Alton GG, Jones LM, Pietz DE (1975) Laboratory techniques in brucellosis. 2nd ed. Geneva, Switzerland: World Health Organization.

16. Orduña A, Almaraz A, Prado A, Gutierrez MP, Garcia-Pascual A, et al. (2000) Evaluation of an immunocapture-agglutination test (Brucellacapt) for the serodiagnosis of human brucellosis. J Clin Microbiol 38: 4000-4005.

17. Kattar MM, Zalloua PA, Araj GF, Samaha-Kfoury J, Shbaklo H, et al. (2007) Development and evaluation of real-time polymerase chain reaction assays on whole blood and paraffin-embedded tissues for rapid diagnosis of human brucellosis. Diagn Microbiol Infect Dis 59: 23-32.
18. Laifer G, Widmer AF, Frei R, Zimmerli W, Fluckiger U (2004) Polymerase chain reaction for Mycobacterium tuberculosis: impact on clinical management of refugees with pulmonary infiltrates. Chest 125: 981-986.

19. Cheng VC, Yam WC, Hung IF, Woo PC, Lau SK, et al. (2004) Clinical evaluation of the polymerase chain reaction for the rapid diagnosis of tuberculosis. J Clin Pathol 57: 281-285.

20. Hasaneen NA, Zaki ME, Shalaby HM, El-Morsi AS (2003) Polymerase chain reaction of pleural biopsy is a rapid and sensitive method for the diagnosis of tuberculous pleural effusion. Chest 124: 2105-2111.

21. Kami M, Fukui T, Ogawa S, Kazuyama Y, Machida U, et al. (2001) Use of realtime PCR on blood samples for diagnosis of invasive aspergillosis. Clin Infect Dis 33: 1504-1512.

22. Smith K, Diggle MA, Clarke SC (2004) Automation of a fluorescence-based multiplex PCR for the laboratory confirmation of common bacterial pathogens. J Med Microbiol 53: 115-117.

23. Rimek D, Tyagi S, Kappe R (2002) Performance of an IS6110-based PCR assay and the COBAS AMPLICOR MTB PGR system for detection of Mycobacterium tuberculosis complex DNA in human lymph node samples. J Clin Microbiol 40: 3089-3092.

24. Navarro E, Escribano J, Fernandez J, Solera J (2002) Comparison of three different PCR methods for detection of Brucella spp in human blood samples. FEM Immunol Med Microbiol 34: 147-151.

25. Debeaumont C, Falconnet PA, Maurin M (2005) Real-time PCR for detection of Brucella spp. DNA in human serum samples. Eur J Clin Microbiol Infect Dis 24: $842-845$.

26. Queipo-Ortuno MI, Colmenero JD, Baeza G, Morata P (2005) Comparison between LightCycler Real-Time Polymerase Chain Reaction (PCR) Assay with Serum and PCR-Enzyme-Linked Immunosorbent Assay with Whole Blood Samples for the Diagnosis of Human Brucellosis. Clin Infect Dis 40: 260-264.

27. Gillespie SH, McHugh TD, Newport LE (1997) Specificity of IS6110-based amplification assays for Mycobacterium tuberculosis complex. J Clin Microbiol 35: 799-801.

28. Park DY, Kim JY, Choi KU, Lee JS, Lee CH, et al. (2003) Comparison of polymerase chain reaction with histopathologic features for diagnosis of tuberculosis in formalin-fixed, paraffin-embedded histologic specimens. Arch Pathol Lab Med 127: 326-330.

29. Broccolo F, Scarpellini P, Locatelli G, Zingale A, Brambilla AM, et al. (2003) Rapid Diagnosis of Mycobacterial Infections and Quantitation of Mycobacterium tuberculosis Load by Two Real-Time Calibrated PCR Assays. J Clin Microbiol 41: 4565-7452.

30. Supply P, Magdalena J, Himpens S, Locht C (1997) Identification of novel intergenic repetitive units in a mycobacterial two-component system operon. Mol Microbiol 26: 991-1003. 